\title{
Transfusion practice varies widely in cardiac surgery: Results from a national registry
}

\author{
Zoe K. McQuilten, MBBS, ${ }^{\mathrm{a}, \mathrm{b}}$ Nick Andrianopoulos, MBBS, MBiostat, ${ }^{\mathrm{a}}$ Erica M. Wood, MBBS, ${ }^{\mathrm{a}, \mathrm{c}}$ \\ Merrole F. Cole-Sinclair, MBBS, ${ }^{\mathrm{d}}$ John J. McNeil, PhD, MBBS, ${ }^{\text {a }}$ Peter A. Cameron, MD, MBBS, ${ }^{a}$ \\ Christopher M. Reid, PhD, ${ }^{a}$ Andrew E. Newcomb, MBBS, ${ }^{e}$ Julian A. Smith, MBBS, MS, ${ }^{f, g}$ and \\ Louise E. Phillips, $\mathrm{PhD}^{\mathrm{a}}$
}

\begin{abstract}
Objectives: Evidence is accumulating of adverse outcomes associated with transfusion of blood components. If there are differences in perioperative transfusion rates in cardiac surgery, and what hospital factors may contribute, requires further investigation.
\end{abstract}

\begin{abstract}
Methods: Analysis of 42,743 adult patients who underwent 43,482 procedures from 2005 to 2011 at 25 Australian hospitals, according to the Australian and New Zealand Society of Cardiac and Thoracic Surgeons Cardiac Surgery Database. Multiple logistic regression examined associations of patient and hospital characteristics with transfusion of $\geq 1$ red blood cell (RBC) unit; platelet (PLT), fresh frozen plasma (FFP), and cryoprecipitate (CRYO) doses; and $\geq 5$ RBC units, from surgery until hospital discharge.
\end{abstract}

Results: Procedures included 24,222 (55\%) isolated coronary artery bypass grafts, 7299 (17\%) isolated valve, $4714(11 \%)$ coronary artery bypass graft and valve, and $7247(17 \%)$ other procedures. After adjustment for various patient and procedure characteristics, transfusion rates varied across hospitals for $\geq 1 \mathrm{RBC}$ unit from $22 \%$ to $67 \%, \geq 5$ RBC units from $5 \%$ to $25 \%, \geq 1$ PLT dose from $11 \%$ to $39 \%, \geq 1$ FFP dose from $11 \%$ to $48 \%$ and $\geq 1$ CRYO dose from $1 \%$ to $20 \%$. Hospital characteristics, including state or territory, private versus public, and teaching versus nonteaching, were not associated with variation in transfusion rates.

Conclusions: Variation in transfusion of all components and large volume RBC was identified, even after adjustment for patient and procedural factors known to influence transfusion, and this was not explained by hospital characteristics. (J Thorac Cardiovasc Surg 2014;147:1684-90)

From the Department of Epidemiology and Preventive Medicine, ${ }^{\mathrm{a}}$ Monash University, Melbourne, Victoria, Australia; Transfusion Medicine Services and Research and Development, ${ }^{\mathrm{b}}$ Australian Red Cross Blood Service, Melbourne, Victoria, Australia; Department of Clinical Haematology, ${ }^{\mathrm{c}}$ Monash University, Melbourne, Victoria, Australia; Haematology Department, ${ }^{\mathrm{d}}$ St Vincent's Hospital, Fitzroy, Victoria, Australia; University of Melbourne Department of Surgery (Cardiothoracic Surgery), ${ }^{\mathrm{e}}$ St Vincent's Hospital, Melbourne, Fitzroy, Victoria, Australia; Department of Surgery, ${ }^{\mathrm{f}}$ Monash Medical Centre, Monash University, Victoria, Australia; and Department of Cardiothoracic Surgery, ${ }^{\mathrm{g}}$ Monash Medical Centre, Victoria, Australia.

Z.M. is the recipient of an Australian National Health and Medical Research Council (NHMRC) Postgraduate Scholarship (No. APP1017942). C.R. is the recipient of an Australian NHRMC Senior Research Fellowship (No. APP 1045862). This project was funded as part of an Australian NHMRC Partnership grant between the Australian Red Cross Blood Service, the Victorian Government Department of Health, and Monash University. NHMRC ID No. 546291. The Australian and New Zealand Society of Cardiac and Thoracic Surgeons National Cardiac Surgery Database Program is funded by the Department of Health Victoria, and the Health Administration Corporation and the Clinical Excellence Commission, New South Wales, Australia. The Australian government fully funds the Australian Red Cross Blood Service for the provision of blood products and services to the Australian Community.

Disclosures: Authors have nothing to disclose with regard to commercial support.

Received for publication March 17, 2013; revisions received Oct 6, 2013; accepted for publication Oct 29, 2013; available ahead of print Dec 12, 2013.

Address for reprints: Zoe K. McQuilten, MBBS, The Alfred Centre, 99 Commercial Rd, Melbourne, Victoria 3004, Australia (E-mail: zoe.mcquilten@monash.edu). $0022-5223 / \$ 36.00$

Copyright (c) 2014 by The American Association for Thoracic Surgery http://dx.doi.org/10.1016/j.jtcvs.2013.10.051
$\mathcal{B}$ Supplemental material is available online.

A substantial proportion of blood components worldwide are issued to patients undergoing cardiac surgery. In Australia this is the second most common surgical indication for red blood cell (RBC) use; the largest single indication for fresh frozen plasma (FFP), accounting for approximately $15 \%$ of all plasma use; and the second largest indication for platelet (PLT) transfusion after hematology and oncology. ${ }^{1,2}$ Despite the significant use of blood components by patients undergoing cardiac surgery, the evidence to guide transfusion therapy is limited, particularly for components other than RBCs. There have been few studies on the optimal triggers for RBC transfusion, and these have been mostly in other clinical settings. ${ }^{3,4}$ Studies on the use of FFP and PLT in cardiac surgery are also limited, with varying results regarding outcomes. $^{5-8}$

There is evidence of significant variation in the transfusion rates of blood components in cardiac surgery between institutions and individual clinicians, ${ }^{9-12}$ and this variation has been shown to continue following publication of 


\section{Abbreviations and Acronyms \\ ANZSCTS $=$ Australian and New Zealand Society \\ of Cardiac and Thoracic Surgeons \\ CABG = coronary artery bypass graft \\ $\mathrm{CRYO}=$ cryoprecipitate \\ FFP $\quad=$ fresh frozen plasma \\ PLT = platelet \\ $\mathrm{RBC} \quad=$ red blood cell}

transfusion practice guidelines. ${ }^{13}$ A previous small Australian survey conducted in 2004 reported substantial variation in $\mathrm{RBC}$ use between institutions following cardiac surgery. ${ }^{14}$ It is not known if these differences persist, if this also applies to the use of non-RBC components, and if hospital characteristics contribute to differences in practice. In our study, we investigated if significant variation exists in blood product use in cardiac surgery, after adjusting for patient-related variables that might reasonably influence the need for transfusion. We also investigated if hospital characteristics account for variation in transfusion rates after adjusting for patient-level characteristics.

\section{METHODS \\ Patients}

All cardiac surgery patients aged 18 years or older reported to the Australian and New Zealand Society for Cardiac and Thoracic Surgery (ANZSCTS) Cardiac Surgery Database, between January 1, 2005, and December 31, 2011, from 25 Australian hospitals, were included in the study. Not all 25 hospitals reported for the entire study duration; however, once reporting commenced all consecutive cases were included.

During this period there were a total of 43,482 procedures recorded in 42,743 adult patients at the 25 hospitals. These included isolated coronary artery bypass graft (CABG) in 24,222 (55\%), isolated valve in 7299 $(17 \%), \mathrm{CABG}$ and valve in $4714(11 \%)$, and other procedure in 7247 $(17 \%)$. Procedures $(n=147)$ in patients younger than age 18 years were excluded.

\section{ANZSCTS Cardiac Surgery Database}

The ANZSCTS Cardiac Surgery Database prospectively collects information on all adult patients undergoing cardiac surgery at participating hospitals using a standardized data set and definitions, including patient demographics, preoperative risk factors, preoperative medications, intraoperative details, transfusion therapy received (including number of units of RBCs, PLTs, FFP, and cryoprecipitate [CRYO]), length of stay, complications, and patient outcomes. ${ }^{15}$

\section{Statistical Methods}

Summary statistics for continuous data are reported as mean and standard deviation or median and interquartile range as appropriate, and as number and percent for categorical variables.

Binary categorical variables for the outcomes of interest were created: $\geq 1$ RBC unit, large-volume RBC transfusion ( $\geq 5$ RBC units), lowvolume RBC transfusion ( 1 or $2 \mathrm{RBC}$ units), $\geq 1 \mathrm{FFP}$ adult equivalent dose, $\geq 1$ PLT adult equivalent dose, and $\geq 1$ CRYO adult equivalent dose. Logistic regression analyses explored the association between covariates, including hospital site, and outcomes, using a backward stepwise approach. Variables that were associated with the outcomes of interest with a $P$ value $<.25$ were considered for the multiple logistic regression models. Pearson's correlation was used to assess variables for potential colinearity, with the more clinically relevant variable selected where present. Covariates considered for the models were those which that reasonably influence a decision to transfuse and included hospital site, patient age, sex, body mass index, peripheral or cerebrovascular disease, prior myocardial infarction, diabetes, New York Heart Association functional class, lung disease, infective endocarditis, preoperative creatinine, medications (including antiplatelet agents within 5 days, anticoagulants, and immunosuppressive therapy), previous cardiothoracic procedure, procedure type and urgency, preoperative shock, and use of intra-aortic balloon pump. Correlation of hospital-adjusted rates of RBC versus PLT and RBC versus FFP were also assessed. Analysis was performed on all procedures and repeated for first-time CABG only.

To explore the association of hospital-level characteristics and outcome, variables for the type of institution (academic affiliation and private or public) and in which area they were located, the median number of cardiac procedures performed annually, and previous covariates were added in multiple multilevel logistic regression models, where hospital site was now modeled as a random effect. ${ }^{16}$

All analyses were performed using the statistical software packages Stata 11.2 (Statacorp LP, College Station, Tex).

\section{RESULTS}

Patient demographics, comorbidities, and surgical and hospital characteristics for all procedures are shown in Table 1. The total number of cardiac surgeries performed at each hospital ranged from 312 to 4193 (median, 1327; IQR, 669-2557) and the median annual number of cardiac surgeries performed at each hospital ranged from 154 to 588 (median, 238; IQR, 164-353).

The most important patient characteristics associated with RBC transfusion in multivariate analysis based on effect size included patient age (odds ratio [OR], 1.1; 95\% confidence interval [CI], 1.0-1.1), New York Heart Association functional class II or greater heart failure (class IV OR, 1.7; 95\% CI, 1.5-1.9) procedure other than isolated $\mathrm{CABG}$ or valve (OR, 2.2; 95\% CI, 1.9-2.3), previous cardiac surgery (OR, $1.3 ; 95 \% \mathrm{CI}, 1.2-1.4)$, urgent (OR, 2.9; 95\% CI, 2.5-3.2) or emergency surgery (OR, 3.7; 95\% CI, 2.1-6.5), and the use of acetylsalicylic acid (OR, 1.2; 95\% CI, 1.1-1.2) or clopidogrel (OR, 1.1; 95\% CI, 1.1-1.2) within 7 days before surgery.

The rate of transfusion, after adjusting for patient and surgical characteristics, of any RBC unit ranged between hospitals from $22 \%$ to $67 \%, \geq 5$ RBC units from $5 \%$ to $24 \%, 1$ or 2 RBC units from $10 \%$ to $34 \%, \geq 1$ PLT dose from $10 \%$ to $39 \%$, $\geq 1$ FFP dose from $10 \%$ to $44 \%$, and $\geq 1$ CRYO dose from $1 \%$ to $21 \%$. The hospital-adjusted rates of transfusion of RBC, PLTs, FFP, and CRYO for all procedures are shown in Figure 1. Similar variation in adjusted rates of blood product use was also present when the analysis was limited to only isolated CABG procedures with no history of previous cardiac surgery (Figure E1). Hospital rates of RBC versus PLT transfusion and RBC versus FFP transfusion after adjustment for patient and surgical characteristics are shown in Figure 2. 
TABLE 1. Patient, surgical, and hospital characteristics for all procedures

\begin{tabular}{|c|c|}
\hline Characteristic & All procedures \\
\hline Total number of procedures & 43,482 \\
\hline \multicolumn{2}{|l|}{ Patient demographics } \\
\hline Age, y & $66 \pm 13$ \\
\hline Male gender & $31,414(72)$ \\
\hline Body mass index & $28.2 \pm 5.4$ \\
\hline Prior myocardial infarction & $16,652(38)$ \\
\hline Cerebrovascular disease & $5027(12)$ \\
\hline Dialysis preoperative & $752(2)$ \\
\hline Lung disease & $5815(13)$ \\
\hline Congestive heart failure & $10,153(23)$ \\
\hline Diabetes & $12,344(28)$ \\
\hline \multicolumn{2}{|l|}{ Medications } \\
\hline Anticoagulants at time of surgery & $8622(20)$ \\
\hline Acetylsalicylic acid within $7 \mathrm{~d}$ & $21,655(50)$ \\
\hline Clopidogrel within $7 \mathrm{~d}$ & $5292(12)$ \\
\hline \multicolumn{2}{|l|}{ Surgical } \\
\hline Previous cardiothoracic surgery & $8320(19)$ \\
\hline \multicolumn{2}{|l|}{ Procedure type } \\
\hline Isolated coronary artery bypass graft & $24,222(55)$ \\
\hline Isolated valve & $7299(17)$ \\
\hline Other & $11,961(28)$ \\
\hline Urgency more than elective & $14,482(34)$ \\
\hline Cardiopulmonary bypass duration, $\min$ & $113 \pm 56$ \\
\hline Crossclamp time, $\min$ & $82 \pm 42$ \\
\hline Intra-aortic balloon pump & $2305(5)$ \\
\hline \multicolumn{2}{|l|}{ Hospital level characteristics ( $n=25$ hospitals) } \\
\hline Academic affiliation $(\mathrm{n}=18)$ & $35,345(81)$ \\
\hline No academic affiliation $(\mathrm{n}=7)$ & 8137 (19) \\
\hline Public $(\mathrm{n}=19)$ & $36,041(83)$ \\
\hline Private $(n=6)$ & $7441(17)$ \\
\hline State $1(\mathrm{n}=9)$ & $23,082(53)$ \\
\hline State $2(\mathrm{n}=9)$ & $13,573(31)$ \\
\hline Other $(\mathrm{n}=7)$ & $6872(16)$ \\
\hline
\end{tabular}

Values are presented as mean \pm standard deviation or $\mathrm{n}(\%)$.

The observed rates of transfusion of RBC, PLT, FFP, and CRYO by hospital-level characteristics are shown in Table 2. After adjustment for patient characteristics (including patient and procedure characteristics) in the multilevel regression analysis, none of the 4 hospital-level characteristics was associated with the transfusion outcomes examined (Table 3 ).

\section{DISCUSSION}

This nationwide analysis of 43,529 cardiac surgical procedures performed at 25 hospitals within Australia demonstrated substantial variation in hospital rates of transfusion of blood components, after adjusting for patient and surgical characteristics, which was not accounted for by the hospital characteristics examined. The finding of variation in blood product use is consistent with a previous Australian study and other international studies that have demonstrated variation in transfusion of RBCs,${ }^{14}$ PLTs, and plasma in cardiac surgery. ${ }^{9-12,17,18}$

Substantial variation in both low volume and large volume RBC transfusion across the 25 institutions was identified, and this variation persisted after adjusting for patient and surgical characteristics that might reasonably influence a decision to transfuse and limiting the analysis to isolated CABG. It is not surprising that individual clinician preference or institutional practice may influence the decision for a low volume RBC transfusion during the perioperative period. However, the requirement of large volume transfusion also appears to be in part dependent on institutional practice even after adjusting for patient and surgical characteristics, including the need for reoperation to control bleeding. Because we did not examine rates of perioperative blood loss between sites, it is not possible from our study to determine if the variation in large volume transfusion is due to differences in bleeding complications across sites or due to a difference in the preferred approach to manage large volume blood loss. However, another study ${ }^{17}$ that demonstrated variation in rates of massive transfusion following cardiac surgery found that perioperative bleeding was relatively consistent between sites, whereas methods for managing this bleeding was more subject to differences.

As observed for RBC transfusion, there was wide variation in the use of FFP, PLT, and CRYO. Hospitals that had higher use of RBCs also tended to have higher transfusion rates of other blood products, and those with a more restrictive use of RBCs had comparatively lower rates of transfusion of other components.

Although there was considerable variation between institutions in transfusion practice, this did not appear to be attributable to hospital-level characteristics, including if the hospital was private or public, had an academic affiliation, or the median number of procedures performed annually. Although differences were evident in observed rates of transfusion between private and public hospitals and also academic status, after adjusting for patient and surgical characteristics, the association of these hospitallevel characteristics with transfusion did not persist. This is in contrast to a study from the United States ${ }^{9}$ linking perioperative RBC use to hospital academic status and geographic region. Although Australia has a relatively uniform health system, there are differences between state jurisdictions in health service structures and the funding of blood products, which may influence practice. However, after adjusting for patient and surgical characteristics, geographic location did not explain the variation in rates of transfusion between institutions.

The finding of variation in transfusion practice in our study, as in other studies, is important for a number of reasons. There is increasing evidence from observational studies of an association between RBC transfusion and 

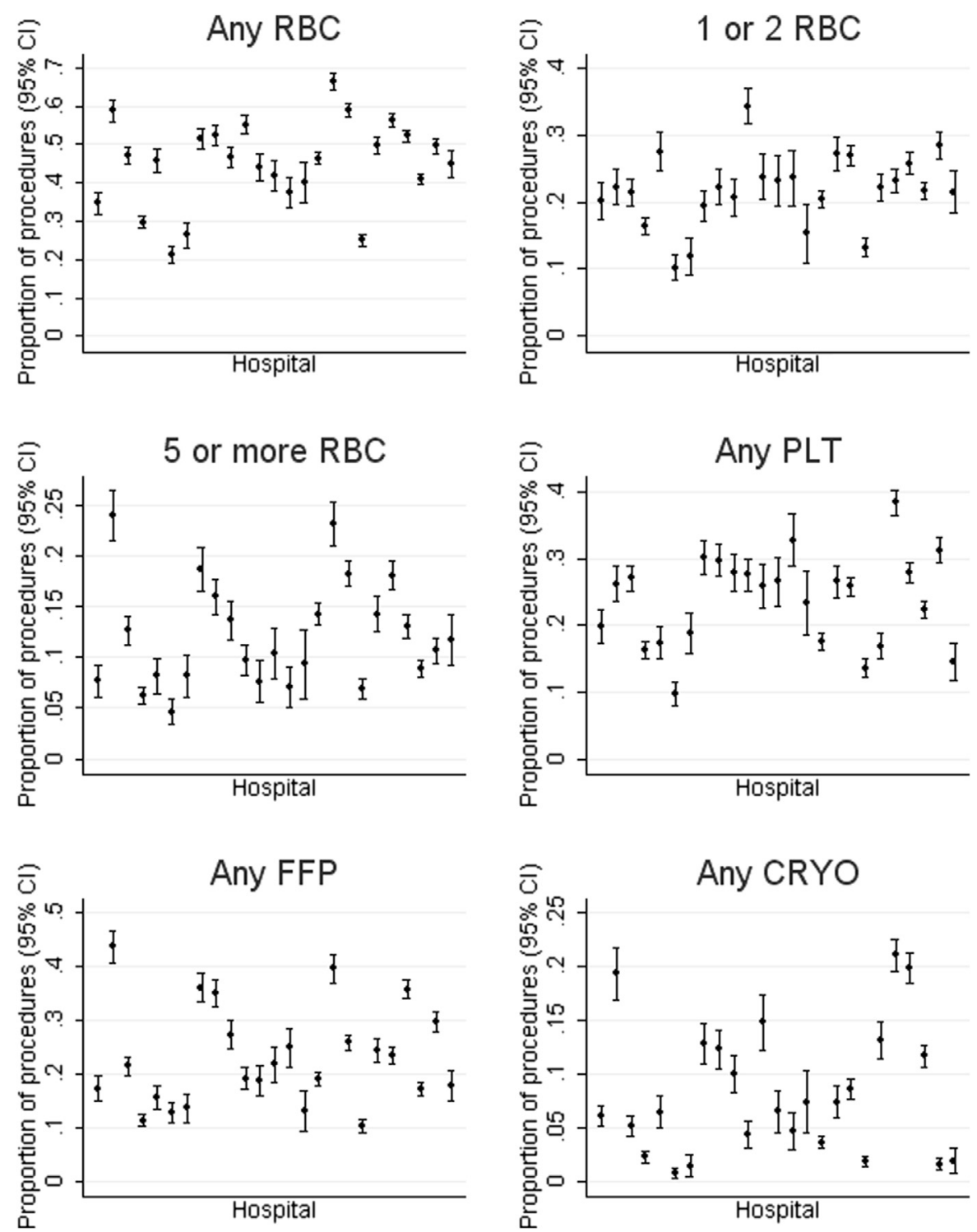

FIGURE 1. Adjusted transfusion outcome rates for all procedures at 25 hospitals. CI, Confidence interval; RBC, red blood cell; PLT, platelet; FFP, fresh frozen plasma; $C R Y O$, cryoprecipitate.

adverse outcomes, including mortality (both short and long-term survival), length of stay, multiorgan failure, infection, and thrombosis. ${ }^{19-21}$ Due to ethical and practical constraints, randomized controlled trials of transfusion compared with nontransfusion in cardiac surgery have not been performed. However, studies comparing different transfusion strategies, including restrictive or reduced transfusion triggers, have shown comparable outcomes. A noninferiority randomized controlled trial of 502 patients undergoing cardiac surgery with cardiopulmonary bypass comparing a restrictive with a more liberal transfusion strategy (maintaining a hematocrit of $24 \%$ vs $30 \%$ ) found comparable mortality and morbidity outcomes. ${ }^{3}$ However, this was a singlecenter study, used fresh nonleukoreduced RBCs, and included less than half of all eligible patients, so the generalizability of the study findings are limited. Other observational studies have demonstrated an association between reduction in blood transfusion rates and improved outcomes. $^{22}$

There are even fewer data to guide transfusion support with other blood components in cardiac surgery. Transfusion of FFP has been associated with increased mortality in cardiac surgery $^{8}$; however, there are conflicting findings on the association of PLT transfusions with outcomes. ${ }^{5,23}$ Although studies have reported on use of fibrinogen concentrate in cardiac surgery, the use of CRYO has not been examined. ${ }^{24}$ The lack of evidence to support transfusion decisions for blood components other than RBCs may contribute to the observed variation in 

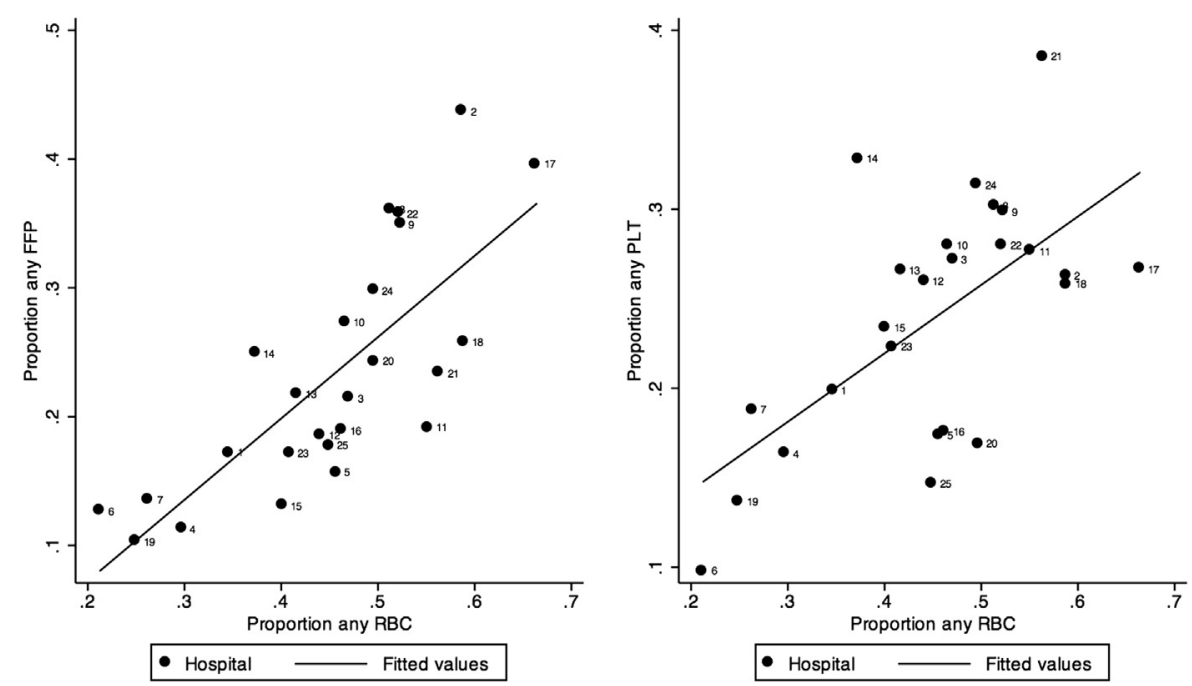

FIGURE 2. Adjusted rates of platelet (PLT), fresh frozen plasma $(F F P)$, and red blood cell $(R B C)$ transfusion, by hospital.

use of these components in cardiac surgery. In fact, in recently published national Perioperative Patient Blood Management Guidelines, ${ }^{24}$ few recommendations or practice points could be made for the use of other blood components due to the lack of evidence. The marked variation in blood product use in cardiac surgery, coupled with limited evidence to inform practice, highlights the requirement for future studies to assess the effect of blood components on patient outcomes.

With the accumulating evidence of the association of RBC transfusion with some adverse outcomes, the increasing costs associated with transfusion and consideration of preservation of limited blood supplies, it has been proposed that RBC transfusion should be included as a quality indicator in cardiac surgery. ${ }^{25}$ With an aging population and advances in medical care, the demand for blood products is expected to rise, placing further demands on a limited resource. In addition, the cost of transfusion is increasing, with reduced donor availability and measures to minimize transfusion risks as contributing factors. ${ }^{26}$ Although reducing unnecessary transfusions is important, there is likely to be a point, albeit as yet undefined, where lowering the transfusion rate any further would pose risks for patients. Therefore, when considering transfusion as a quality indicator, it should be the rate of appropriate transfusion, rather than the lowest transfusion rate, that is the desired outcome.

It has been argued that wide variation in transfusion practice is an indicator of excessive or inappropriate transfusions. ${ }^{27}$ However substantial variation in practice is also a pointer to an inadequate evidence base to guide practice. In this setting, the optimal use of blood products in cardiac surgery has not been well established and therefore the ideal approach to change transfusion practice and reduce variation is not clear.

Our study has demonstrated significant institutional variation in transfusion practice within a relatively uniform health system and with ready access to blood products. However, neither patient, procedure, nor hospital-level characteristics, including academic affiliation or the hospital's location, accounted for this variation. These observed differences should be interpreted in light of the limitations of the study. First, the ANZSCTS Cardiac Surgery Database does not include preoperative or intraoperative hemoglobin, hematocrit, platelet count, or coagulation profile, nor does it collect information on the

TABLE 2. Frequency of blood product use, by hospital-level characteristics

\begin{tabular}{|c|c|c|c|c|c|c|}
\hline Hospital characteristic & Any RBC & RBC (1-2 units) & RBC ( $\geq 5$ units) & PLT & FFP & CRYO \\
\hline Public & $16,389(46)$ & $7812(22)$ & 4595 (13) & $8649(24)$ & $8365(23)$ & $3180(9)$ \\
\hline Private & 3047 (41) & $1484(20)$ & $741(10)$ & $1382(19)$ & 1389 (19) & $450(6)$ \\
\hline \multicolumn{7}{|l|}{ Academic affiliation } \\
\hline Yes & $16,118(46)$ & $7671(22)$ & 4539 (13) & $8571(24)$ & $8266(23)$ & $3171(9)$ \\
\hline No & $3318(41)$ & $1625(20)$ & $797(10)$ & $1460(18)$ & $1488(18)$ & $459(6)$ \\
\hline State 1 & $10,231(44)$ & $4874(21)$ & $2844(12)$ & $5297(23)$ & $4716(20)$ & $2188(10)$ \\
\hline State 2 & $6387(47)$ & $2965(22)$ & $1808(13)$ & $3234(24)$ & $3472(26)$ & $1229(9)$ \\
\hline Other states & $2818(42)$ & $1457(22)$ & $684(10)$ & $1500(22)$ & $1566(23)$ & $213(3)$ \\
\hline
\end{tabular}

Values are presented as n (\%). RBC, Red blood cell; PLT, platelet; FFP, fresh frozen plasma; $C R Y O$, cryoprecipitate. 
TABLE 3. Odds ratio and $95 \%$ confidence intervals of association of hospital-level characteristics and transfusion outcomes for all procedures

\begin{tabular}{|c|c|c|c|c|c|c|}
\hline Hospital characteristic & Any RBC & RBC 1-2 units & $\mathbf{R B C} \geq \mathbf{5}$ units & PLT & FFP & CRYO \\
\hline Public & 1.0 & 1.0 & 1.0 & 1.0 & 1.0 & 1.0 \\
\hline Private & $0.8(0.2-2.9)$ & $0.9(0.4-1.8)$ & $0.8(0.2-2.3)$ & $1.7(0.7-4.3)$ & $0.9(0.3-3.1)$ & $2.2(0.3-17)$ \\
\hline \multicolumn{7}{|l|}{ Academic affiliation } \\
\hline Yes & 1.0 & 1.0 & 1.0 & 1.0 & 1.0 & 1.0 \\
\hline No & $1.1(0.4-4.5)$ & $1.0(0.5-2.0)$ & $1.1(0.3-3.3)$ & $0.5(0.2-1.2)$ & $0.8(0.2-2.6)$ & $0.5(0.1-3.5)$ \\
\hline State 1 & 1.0 & 1.0 & 1.0 & 1.0 & 1.0 & 1.0 \\
\hline State 2 & $1.4(0.8-2.4)$ & $1.2(0.8-1.6)$ & $1.1(0.7-1.9)$ & $1.1(0.7-1.6)$ & $1.6(0.9-2.6)$ & $1.3(0.6-3.4)$ \\
\hline Other states & $1.0(0.6-1.8)$ & $1.0(0.7-1.5)$ & $0.7(0.4-1.2)$ & $1.1(0.6-1.7)$ & $1.2(0.6-2.3)$ & $0.5(0.2-1.3)$ \\
\hline Median number & $0.9(0.9-1.0)$ & $0.9(0.9-1.0)$ & $0.9(0.9-1.0)$ & $0.9(0.9-1.0)$ & $0.9(0.9-1.0)$ & $0.9(0.9-1.0)$ \\
\hline
\end{tabular}

$R B C$, Red blood cell; $P L T$, platelet; FFP, fresh frozen plasma; $C R Y O$, cryoprecipitate. *Odds ratio ( $95 \%$ confidence interval) are from multiple multilevel logistic regression with assignment of random effects for each hospital.

use of autologous blood. Therefore, the rates of transfusion could not be adjusted for these parameters in the multivariate analysis. Second, although the quality of the ANZSCTS data, including accuracy and completeness, has been validated with an external quality audit program, this has not included transfused blood components. ${ }^{15}$ Although we have established a generally high degree of accuracy of our data sources, it is possible that a small part of the institutional variation observed might be attributed to the way in which data on transfused blood components is collected or recorded.

\section{CONCLUSIONS}

These findings from a large and prospectively collected cardiac surgery database demonstrate wide variation in transfusion practice not accounted for by patient or hospital-level characteristics. Many areas remain where the evidence base to inform the use of blood products in cardiac surgery is lacking. Further clinical studies and formal evaluation of the effect of patient blood management programs, rates of transfusion, and patient outcomes, is warranted.

The authors thank the ANZSCTS Data Management Centre, CCRE, Monash University: Professor Chris Reid, Dr Lavinia Tran, and Mrs Angela Brennan; the ANZSCTS Database Program Steering Committee: $\mathrm{Mr}$ Gil Shardey (Chair), Mr Peter Skillington, Mr Julian Smith, Mr Andrew Newcomb, Mr Siven Seevanayagam, Mr Bo Zhang, Mr Hugh Wolfenden, Mr Adrian Pick, Mr Jurgen Passage, Assistant Professor Rob Baker, Professor Chris Reid, Dr Lavinia Tran, and Mr Andrew Clarke.

The following investigators, data managers, and institutions participated in the ANZSCTS Database: Alfred Hospital: Pick A, Duncan J; Austin Hospital: Seevanayagam S, Shaw M; Cabrini Health: Shardey G; Geelong Hospital: Morteza M, Zhang B, Bright C; Flinders Medical Centre: Knight J, Baker R, Helm J, Canning N; Jessie McPherson Private Hospital: Smith J, Baxter H; Hospital: John Hunter Hospital: James A, Scaybrook S; Lake Macquarie Hospital: Dennett B, Mills M; Liverpool Hospital: French B, Hewitt N; Mater Health Services: Diqer AM, Curtis L; Monash Medical Centre: Smith J, Baxter H; Prince of Wales
Hospital: Wolfenden H, Weerasinge D; Royal Melbourne Hospital: Skillington P, Wynne R; Royal North Shore Hospital: Sze D; Royal Perth Hospital: Edwards M, Wright M, Le V. Royal Prince Alfred Hospital: Wilson M, Turner L; Powell, C; Sir Charles Gairdner: Kolybaba M; St George Hospital: Fermanis G, Newbon P; St Vincent's Hospital, VIC: Yii M, Newcomb A, Mack J, Duve K; St Vincent's Hospital, NSW: Spratt P, Hunter T; The Canberra Hospital: Bissaker P, Dean A; Townsville Hospital: Tam R, Farley A; Westmead Hospital: Costa R, Halaka M.

\section{References}

1. Comande M, Waters N, Grigoriadis G, Polizzotto MN, Borosak M, Jolley DJ, et al. Profiling clinical plasma usage to inform supply and contingency planning: finally results from Puppy, the Prospective Utilisation of Platelets and Plasma study. Auckland: Australian and New Zealand Society of Blood Transfusion; 2010.

2. Shortt J, Polizzotto MN, Waters N, Borosak M, Moran M, Comande M, et al. Assessment of the urgency and deferability of transfusion to inform emergency blood planning and triage: the Bloodhound prospective audit of red blood cell use. Transfusion. 2009:49:2296-303.

3. Hajjar LA, Vincent J-L, Galas FRBG, Nakamura RE, Silva CMP, Santos MH, et al. Transfusion requirements after cardiac surgery. JAMA. 2010;304:1559-67.

4. Hebert PC, Wells G, Blajchman MA, Marshall J, Martin C, Pagliarello G, et al. A multicenter, randomized, controlled clinical trial of transfusion requirements in critical care. Transfusion Requirements in Critical Care Investigators, Canadian Critical Care Trials Group. N Engl J Med. 1999;340:409-17.

5. Vamvakas EC. Platelet transfusion and postoperative infection in cardiac surgery. Transfusion. 2007:47:352-4; author reply 54-6.

6. Karkouti K, Wijeysundera DN, Yau TM, Callum JL, Meineri M, Wasowicz M, et al. Platelet transfusions are not associated with increased morbidity or mortality in cardiac surgery. Can J Anaesth. 2006;53:279-87.

7. Bilgin YM, van de Watering LM, Versteegh MI, van Oers MH, Vamvakas EC, Brand A. Postoperative complications associated with transfusion of platelets and plasma in cardiac surgery. Transfusion. 2011;51:2603-10.

8. Murad MH, Stubbs JR, Gandhi MJ, Wang AT, Paul A, Erwin PJ, et al. The effect of plasma transfusion on morbidity and mortality: a systematic review and meta-analysis. Transfusion. 2010;50:1370-83.

9. Bennett-Guerrero E, Zhao Y, O’Brien SM, Ferguson TB, Peterson ED, Gammie JS, et al. Variation in use of blood transfusion in coronary artery bypass graft surgery. JAMA. 2010;304:1568-75.

10. Goodnough LT, Johnston MFM, Toy PTCY. The variability of transfusion practice in coronary artery bypass surgery. JAMA. 1991;265:86-90.

11. Rogers MAM, Blumberg N, Saint S, Langa KM, Nallamothu BK. Hospital variation in transfusion and infection after cardiac surgery: a cohort study. BMC Med. 2009; 7:37.

12. Surgenor D, Churchill W, Wallace E, Rizzo R, McGurk S, Goodnough L, et al The specific hospital significantly affects red cell and component transfusion practice in coronary artery bypass graft surgery: a study of five hospitals. Transfusion. 1998;38:122-34.

13. Stover EP, Siegel LC, Parks R, Levin J, Body SC, Maddi R, et al. Variability in transfusion practice for coronary artery bypass surgery persists despite national 
consensus guidelines: a 24-institution study. Institutions of the Multicenter Study of Perioperative Ischemia Research Group. Anesthesiology. 1998;88:327-33.

14. Daly DJ, Myles PS, Smith JA, Knight JL, Clavisi O, Bain DL, et al Anticoagulation, bleeding and blood transfusion practices in Australasian cardiac surgical practice. Anaesth Intensive Care. 2007;35:760-8.

15. Billah B, Reid CM, Shardey GC, Smith JA. A preoperative risk prediction model for 30-day mortality following cardiac surgery in an Australian cohort. Eur J Cardiothorac Surg. 2010;37:1086-92.

16. Sanagou M, Wolfe R, Forbes A, Reid CM. Hospital-level associations with 30-day patient mortality after cardiac surgery: a tutorial on the application and interpretation of marginal and multilevel logistic regression. BMC Med Res Methodol. 2012;12:28.

17. Karkouti K, Wijeysundera DN, Beattie WS, Callum JL, Cheng D, Dupuis JY, et al. Variability and predictability of large-volume red blood cell transfusion in cardiac surgery: a multicenter study. Transfusion. 2007;47:2081-8.

18. Karkouti K, Beattie S. Pro: the role of recombinant factor VIIa in cardiac surgery. J Cardiothorac Vasc Anesth. 2008;22:779-82.

19. Hillyer CD, Blumberg N, Glynn SA, Ness PM. Transfusion recipient epidemiology and outcomes research: possibilities for the future. Transfusion. 2008;48:1530-7.
20. Murphy GJ, Reeves BC, Rogers CA, Rizvi SIA, Culliford L, Angelini GD Increased mortality, postoperative morbidity, and cost after red blood cell transfusion in patients having cardiac surgery. Circulation. 2007;116:2544-52.

21. Bhaskar B, Dulhunty J, Mullany DV, Fraser JF. Impact of blood product transfusion on short and long-term survival after cardiac surgery: more evidence. Ann Thorac Surg. 2012;94:460-7.

22. Moskowitz DM, McCullough JN, Shander A, Klein JJ, Bodian CA, Goldweit RS, et al. The impact of blood conservation on outcomes in cardiac surgery: is it safe and effective? Ann Thorac Surg. 2010;90:451-8.

23. Karkouti K, Wijeysundera DN, Beattie WS. Platelet transfusions as a risk factor in cardiac surgery. Transfusion. 2007;47:1739-40; author reply 40.

24. National Blood Authority. Patient Blood Management Guidelines: Module 2-Perioperative. Canberra: National Blood Authority; 2012.

25. Shander AS, Goodnough LT. Blood transfusion as a quality indicator in cardiac surgery. JAMA. 2010;304:1610-1.

26. Shander A, Hofmann A, Gombotz H, Theusinger OM, Spahn DR. Estimating the cost of blood: past, present, and future directions. Best Pract Res Clin Anaesthesiol. 2007;21:271-89.

27. Shander A, Puzio T, Javidroozi M. Variability in transfusion practice and effectiveness of strategies to improve it. J Cardiothorac Vasc Anesth. 2012;26:541-4. 

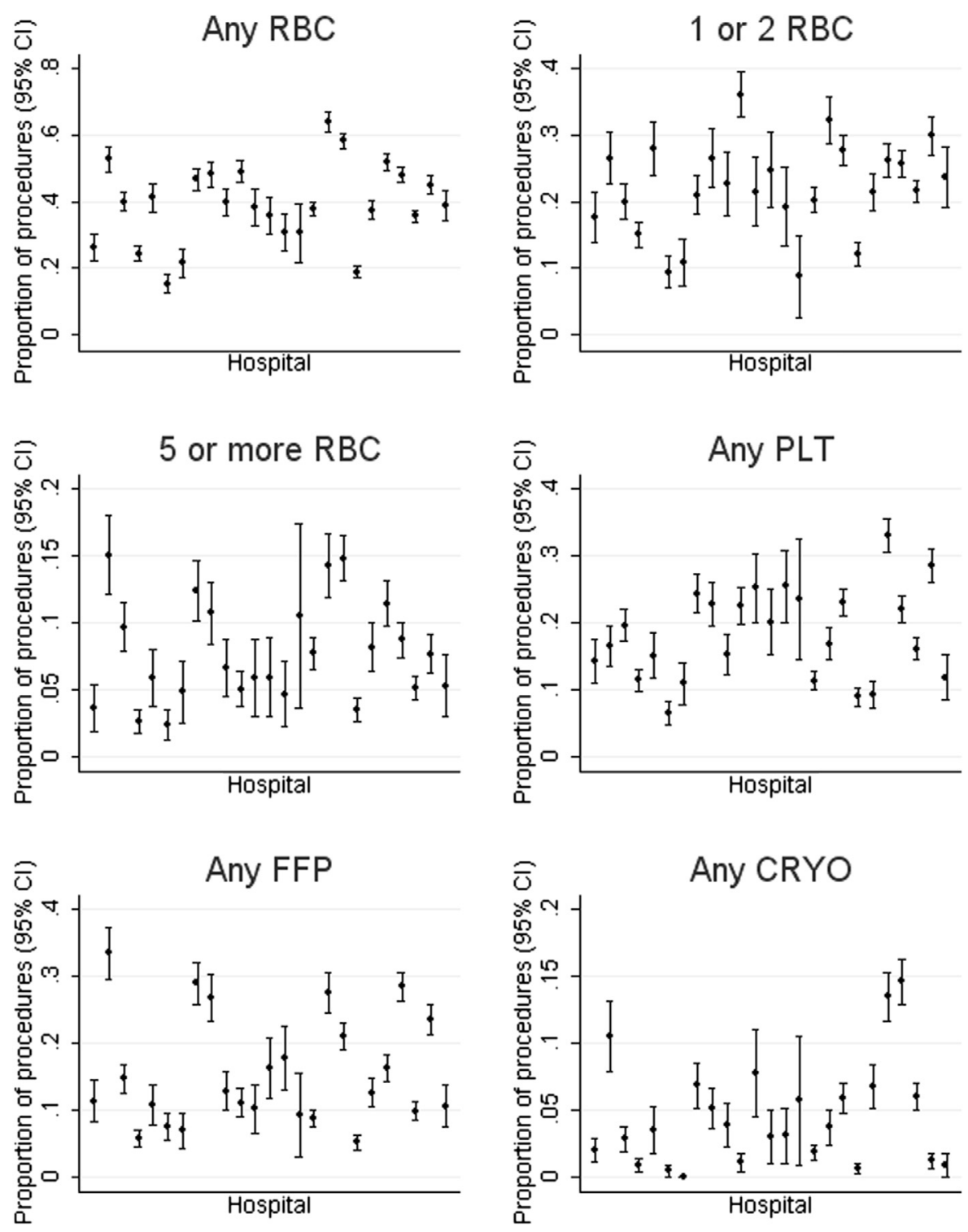

FIGURE E1. Adjusted transfusion outcome rates for primary coronary artery bypass graft only for 25 hospitals. $C I$, Confidence interval; $R B C$, red blood cell; PLT, platelet; FFP, fresh frozen plasma; $C R Y O$, cryoprecipitate. 